\title{
Systemic and intravesical adoptive cell therapy of tumor-reactive $T$ cells can decrease bladder tumor growth in vivo
}

\author{
Brittany L Bunch (D) , ${ }^{1}$ Jennifer Morse, ${ }^{1}$ Sarah Asby, ${ }^{1}$ Jamie Blauvelt, ${ }^{1}$ \\ Ahmet M Aydin, ${ }^{2}$ Patrick Innamarato (D) , ${ }^{1}$ Ali Hajiran, ${ }^{2}$ Matthew Beatty, ${ }^{1}$ \\ Michael Poch, ${ }^{2,3}$ Shari Pilon-Thomas ${ }^{1,3,4}$
}

To cite: Bunch BL, Morse J, Asby S, et al. Systemic and intravesical adoptive cell therapy of tumor-reactive $T$ cells can decrease bladder tumor growth in vivo. Journal for ImmunoTherapy of Cancer 2020;8:e001673. doi:10.1136/ jitc-2020-001673

- Additional material is published online only. To view, please visit the journal online (http://dx.doi.org/10.1136/jitc2020-001673).

Accepted 18 November 2020

\section{Check for updates}

(c) Author(s) (or their employer(s)) 2020. Re-use permitted under CC BY-NC. No commercial re-use. See rights and permissions. Published by BMJ.

'Department of Immunology, H. Lee Moffitt Cancer Center and Research Institute, Tampa,

Florida, USA

${ }^{2}$ Department of Genitourinary Oncology, H. Lee Moffitt Cancer Center and Research Institute, Tampa, Florida, USA

${ }^{3}$ Immunology Program, H. Lee Moffitt Cancer Center and Research Institute, Tampa, Florida, USA

${ }^{4}$ Department of Oncologic Sciences, University of South Florida, Morsani College of Medicine, Tampa, Florida, USA

Correspondence to Dr Shari Pilon-Thomas; shari.pilon-thomas@moffitt.org

\section{ABSTRACT}

Background The therapeutic armamentarium of bladder cancer has been recently enriched with the introduction of new therapies including immune checkpoint inhibitors, receptor tyrosine kinase inhibitors and antibody drug conjugates, however treatment responses and duration of responses are still less than expected. Adoptive cellular therapy (ACT) using tumor-infiltrating lymphocytes (TILs) has potential to treat bladder cancer, as previously demonstrated by successful expansion of tumor reactive T cells from human bladder tumors.

Methods A model system using 0T-I T cells and an ovalbumin expressing MB49 tumor cell line (MB490VA) was developed to study ACT in bladder cancer. Systemic ACT-treated mice were given T cells intravenously after lymphodepleting chemotherapy and followed by interleukin (IL)-2 administration. Intravesical ACT treated mice were given $T$ cells directly into the bladder, without chemotherapy or IL-2. TILs were isolated from MB49 orthotopic tumors and expanded ex vivo in IL-2. Immune cell infiltrates were analyzed by flow cytometry. T cell infiltration was studied using a CXCR3 blocking antibody. Results Systemic ACT-treated mice had a decrease in tumor growth, increase in T cell infiltration and long-term immune protection compared with control-treated mice. OT-I T cells delivered intravesically were able to control tumor growth without lymphodepleting chemotherapy or IL-2 in MB490VA orthotopic tumors. Intravesical delivery of TIL expanded from MB49 tumors was also able to decrease tumor growth in mice with MB49 orthotopic tumors. Blocking CXCR3 on OT-I T cells prior to intravesical delivery decreased $\mathrm{T}$ cell infiltration into the tumor and prevented the control of tumor growth.

Conclusions This study demonstrates how TIL therapy can be used in treating different stages of bladder cancer.

\section{INTRODUCTION}

In 2020, it is estimated that there will be 81000 new cases of urinary bladder cancer and 18000 deaths attributed to the disease in the USA. ${ }^{1}$ Approximately $70 \%-75 \%$ of all new bladder cancer cases present with superficial or non-muscle bladder cancer (NMIBC) in which the disease is confined to the mucosa or submucosa. ${ }^{23}$ Per clinical guidelines, intermediate-risk and high-risk NMIBC are initially treated locally with transurethral resection (TURBT) followed by therapeutic or adjuvant intravesical BCG. ${ }^{45}$ BCG was one of the first Food and Drug Administration (FDA)-approved immunotherapies to treat cancer in the 1970 s, but over the past decade BCG supply has become increasingly limited due to manufacturing shortages. ${ }^{6} 7$ More recently, the FDA has approved systemic immune checkpoint inhibitors targeting programmed cell death protein 1 (PD-1) and programmed death-ligand 1 (PD-L1) as treatment for patients with BCG unresponsive carcinoma in situ of the bladder and for patients with advanced bladder cancer who have previously received or are ineligible for cisplatin-based chemotherapy. ${ }^{8-13}$ However, the objective treatment response to immune checkpoint inhibitors in patients with bladder cancer remains lower than expected with an objective response rate ranging between $15 \%$ and $25 \%$ in all platinum pretreated advanced bladder cancer cases and about $25 \%$ and $30 \%$ in cases with high biomarker expression. ${ }^{8-1214}$ Among the $20 \%-25 \%$ of patients who present with muscle-invasive bladder cancer (MIBC) at initial diagnosis, about $20 \%-40 \%$ eventually experience disease recurrence after radical cystectomy. ${ }^{15}$ The survival of patients with metastatic bladder cancer, approximately $5 \%$ of all cases at diagnosis, is $<12$ months after failing first-line cisplatinbased chemotherapy. ${ }^{16} \quad 17$ The FDA has recently approved enfortumab vedotin, an antibody-drug conjugate targeting nectin-4, and erdafitinib, a fibroblast growth factor receptor tyrosine kinase inhibitor, in heavily pretreated patients with advanced disease. Enfortumab vedotin has an overall response rate of 44\%; however, estimated overall survival is still $<12$ months. ${ }^{18}$ Likewise erdafitinib demonstrated a limited overall response rate $(40 \%)$ in a particular subset of patients 
harboring genetic alterations of fibroblast growth factor receptor, with a limited duration of treatment response (an approximate progression-free and overall survival of 6 and 12 months, respectively). ${ }^{19}$ Therefore, there is a current pressing need to identify novel treatment strategies for patients with bladder cancer with high-risk localized, locally advanced and metastatic disease.

Adoptive cellular therapy (ACT) of tumor-infiltrating lymphocytes (TILs) is a personalized immunotherapy approach to treat solid tumors. Surgically resected tumor specimens are minced into small fragments $\left(1-3 \mathrm{~mm}^{3}\right)$ and cultured in high-dose interleukin (IL)-2 to promote expansion of $\mathrm{T}$ cells from within the tumor. Tumorreactive TIL is selected, expanded to high numbers $\left(10^{10}\right)$, and then reinfused into the patient following nonmyeloablative chemotherapy (NMAC). ACT of TIL has been successful in improving overall survival in patients with metastatic melanoma. ${ }^{20}$ Similar to melanoma, bladder cancer has been demonstrated to be an immunogenic tumor type, having one of the highest tumor mutation burdens among all cancer types, with resulting high levels of predicted neoantigen expression. ${ }^{22}{ }^{23}$ Moreover, increased levels of $\mathrm{CD}^{+}$cytotoxic $\mathrm{T}$ cell infiltration within the tumor microenvironment has been associated with improved survival in patients with bladder cancer. ${ }^{24} 25$ Given these features, it is plausible that TIL therapy may be effective in targeting and treating both localized and metastatic bladder cancer tumors.

Our lab has previously shown the feasibility of expanding tumor-reactive $\mathrm{T}$ cells from patients with bladder cancer in vitro. ${ }^{26}$ In this study, we investigated the ability of tumorreactive $\mathrm{T}$ cells to treat bladder cancer in vivo, using both systemic and intravesical TIL delivery methods. We found that intravesically delivered $\mathrm{T}$ cells are able to infiltrate bladder cancer tumors in part through CXCR3 signaling and are able to delay tumor growth. Results from this study provide rationale for delivering TIL either systemically or intravesically to treat bladder cancer.

\section{METHODS}

\section{Animals}

Female C57BL/6 mice were purchased from Charles River Laboratories (Indianapolis, Indiana, USA). OT-I transgenic mice (C57BL/6-Tg (TcraTcrb) $1100 \mathrm{Mjb} / \mathrm{J}$ ) were purchased from The Jackson Laboratory. Mice were housed and bred in the Comparative Medicine Facility at Moffitt Cancer Center where they were monitored daily. When tumors reached $400 \mathrm{~mm}^{2}$ (subcutaneous) or 250-300 $\mathrm{mm}^{3}$ (orthotopic) mice were humanely euthanized with $\mathrm{CO}_{2}$ followed by cervical dislocation.

\section{Cell lines and cell culture}

MB49 murine bladder cancer cells were a kind gift from Dr Jeffery Schlom (National Cancer Institute, Bethesda, Maryland, USA) ${ }^{27}$ An ovalbumin (OVA) expressing fluorescent MB49 cell line (MB49OVA) was generated by exposing cells to supernatants containing a lentiviral vector comprising a fluorescent $\mathrm{ZsGreen}(\mathrm{ZsG})$ protein and OVA. The viral supernatant was a kind gift from the Dr Brian Ruffell laboratory (H. Lee Moffitt Cancer Center, Tampa, Florida, USA). After transduction, ZsGreen ${ }^{\text {hi }}$ tumor cells were sorted by FACS using BD FACSAria. MB49OVA tumor cells were passaged in vitro 4 times. OVA expression was confirmed by staining for $\mathrm{H} 2-\mathrm{K}^{\mathrm{b}}$ bound to SIINFEKL peptide (25-D1.16, BioLegend). Cell lines were cultured in Complete Medium (CM) consisting of RPMI 1640 supplemented with $10 \%$ heat-inactivated fetal calf serum, $0.1 \mathrm{mM}$ non-essential amino acids, $1 \mathrm{mM}$ sodium pyruvate, $2 \mathrm{mM}$ fresh L-glutamine, $100 \mathrm{mg} / \mathrm{mL}$ streptomycin, $100 \mathrm{U} / \mathrm{mL}$ penicillin, $50 \mathrm{mg} / \mathrm{mL}$ gentamycin, 0.5 $\mathrm{mg} / \mathrm{mL}$ fungizone (all from Life Technologies, Rockville, Maryland, USA) and $0.05 \mathrm{mM}$ 2-ME (Sigma-Aldrich, St. Louis, Missouri, USA). After thawing, cells were passaged no more than 10 times and routinely tested negative for mycoplasma.

\section{T cell isolation and culture}

Mice were inoculated with $5.0 \times 10^{5}$ MB49 or MB49OVA cells subcutaneously at the right ventral abdomen or $1.0 \times 10^{5} \mathrm{MB} 49$ or MB49OVA cells orthotopically. T cells from MB49 or MB49OVA tumors were isolated using EasySep Mouse CD90.2 Positive Selection Kit II (Stem Cell Technologies) according to the manufacturer's protocol. Isolated cells were plated in CM+IL-2 (100 IU, Prometheus).

\section{Systemic ACT treatment model}

MB49OVA cells $\left(5.0 \times 10^{5}\right)$ were injected subcutaneously at the right ventral abdomen. Once tumors were palpable, mice received intraperitoneal injections of cyclophosphamide $(200 \mu \mathrm{g})$ followed by fludarabine 24 hours later (100 $\mu \mathrm{g})$. One day after fludarabine, OT-I T cells were isolated from splenocytes using EasySep Mouse $\mathrm{CD}^{+} \mathrm{T}$ Cell Isolation Kit (Stem Cell Technologies) according to the manufacturer's protocol and delivered intravenously in 250 $\mu \mathrm{L}$ phosphate-buffered saline (PBS). IL-2 $\left(2.5 \mathrm{e}^{5} \mathrm{IU}\right)$ was given intraperitoneally every 12 hours for 3 days following $\mathrm{T}$ cell injections. Control mice did not receive $\mathrm{T}$ cells or IL-2 injections. Tumor size was measured every 2-3 days.

\section{Intravesical treatment model}

MB49 or MB49OVA cells were injected orthotopically. ${ }^{28}$ Briefly, mice were put under anesthesia and catheters were placed. Poly-L-lysine $(50 \mu \mathrm{L}$ at $1 \mu \mathrm{g} / \mathrm{mL})$ was injected into the bladder for $10 \mathrm{~min}$. Bladders were washed with PBS $(50 \mu \mathrm{L})$ and tumor cells were injected for $30 \mathrm{~min}\left(1.0 \times 10^{5}\right.$ cells in $100 \mu \mathrm{L}$ of PBS). The presence of tumor was confirmed by ultrasound-guided imaging using the Vevo 2100 imaging system (FUJIFILM VisualSonics). Approximately 7 days after injection when tumors were detected, OT-I T cells or MB49 TILs (isolated as described above) were infused directly into the bladder while mice were under anesthesia with catheters in place for 3 hours. Mice were not given lymphodepleting chemotherapy prior to 
A

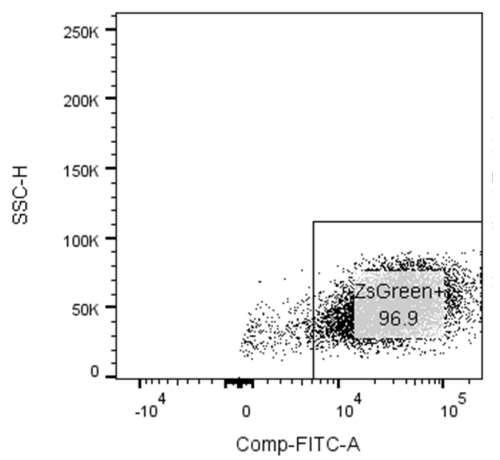

C

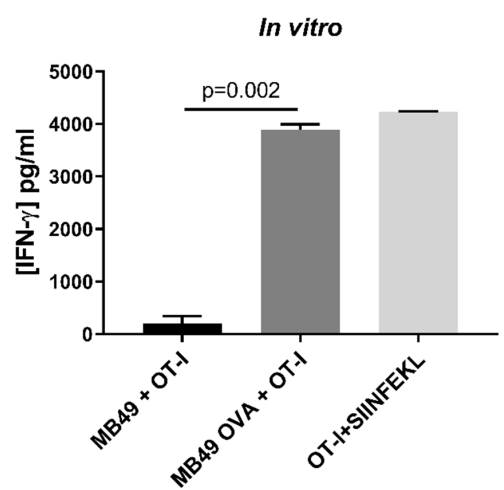

B

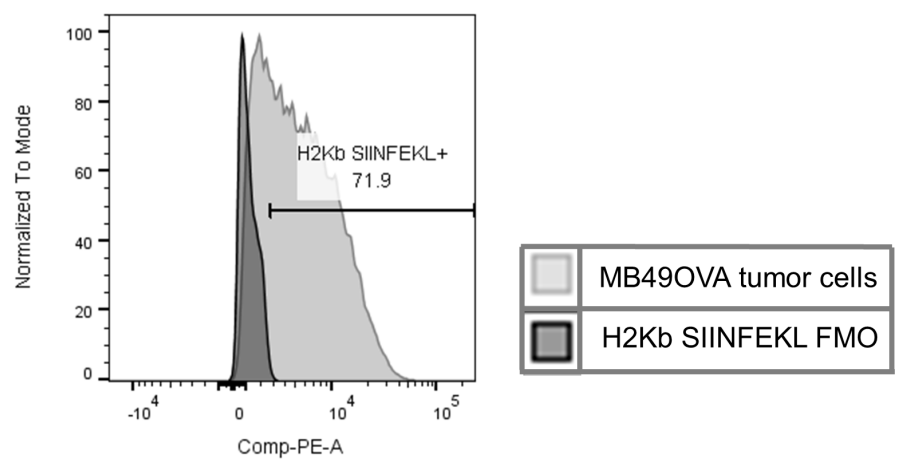

D

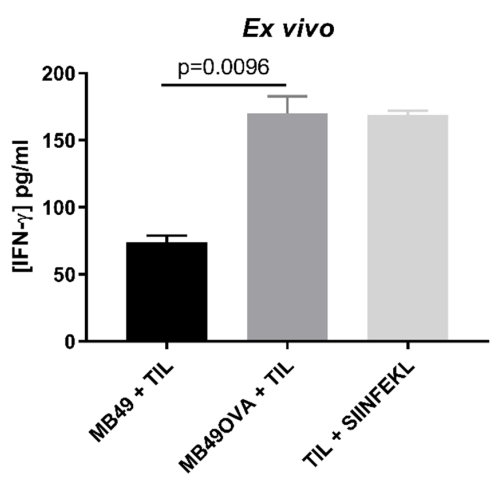

Figure 1 OT-I T cells are specific for bladder cancer cell line ovalbumin (OVA) expressing MB49 tumor cell line (MB49OVA). MB49 cells were infected with a lentiviral vector expressing ZsGreen and OVA. ZsGreen ${ }^{\text {hi }}$ cells were FACS sorted. Successful (A) incorporation of ZsGreen and (B) OVA SIINFEKL presentation of major histocompatibility complex class I expression was confirmed by flow cytometry. IFN- $\gamma$ levels were evaluated by ELISA after co-culture of (C) OT-I T cells isolated from naïve mouse splenocytes or (D) tumor-infiltrating lymphocyte (TIL) isolated from MB49OVA tumors 10:1 with irradiated MB49, MB49OVA or SIINFEKL peptide as a positive control.

T cell delivery or IL-2 post-T cell delivery. Tumor size was measured by ultrasound every $3-4$ days.

\section{Murine tissue processing}

Tumors were processed into a single cell suspension by enzymatic digestion using Hanks' Balanced Salt Soltuion (HBSS) (Life Technologies) containing $1 \mathrm{mg} / \mathrm{mL}$ collagenase, $0.1 \mathrm{mg} / \mathrm{mL}$ DNAse I and $2.5 \mathrm{U} / \mathrm{mL}$ of hyaluronidase (all from Sigma-Aldrich). Samples were incubated at $37^{\circ} \mathrm{C}$ for $45 \mathrm{~min}$ with constant agitation. Samples were passed through a $70 \mu \mathrm{m}$ strainer and washed with $\mathrm{CM}$. Red blood cells (RBCs) were lysed using RBC lysis buffer (Biolegend) for $5 \mathrm{~min}$. Spleens were processed by physical dissociation through a $100 \mu \mathrm{m}$ strainer followed by RBC lysis.

\section{Flow cytometry and tetramer staining}

Tumors and spleens were processed into single cell suspensions as described above. Cells $\left(1 \times 10^{6}\right)$ were washed with $1 \mathrm{~mL}$ PBS. Zombie NIR viability dye (Biolegend, 1:1000) was added to each sample and incubated at room temperature for $30 \mathrm{~min}$ in the dark. Samples were washed with flow buffer (1.0 L PBS, $5 \%$ heat-inactivated fetal bovine serum, $1 \mathrm{mM}$ EDTA, $0.1 \%$ sodium azide) and stained for OVA tetramer (MBL International, Woburn, Massachusetts, catalog\# TB5001-1) at $4^{\circ} \mathrm{C}$ for $20 \mathrm{~min}$ in the dark followed by cell surface markers CD3 (catalog\# 565643), CD8 (catalog\# 558106), CD4 (catalog\# 550954), CXCR3 (catalog\# 562152) and CD45.1 (catalog\# 560578, all from BD Biosciences, San Jose, California, USA) at $4^{\circ} \mathrm{C}$ for $20 \mathrm{~min}$ in the dark. Samples were run on a FACSCelesta flow cytometer (BD Biosciences) and analyzed using FlowJo V.10 software.

\section{Assessment of interferon-gamma by ELISA}

OT-I T cells were plated in a co-culture 10:1 with irradiated MB49 or MB49OVA tumor cells or OVA SIINFEKL peptide $(1 \mu \mathrm{g} / \mathrm{mL})$ as a positive control. Supernatants were collected after 48 hours. Interferon-gamma (IFN- $\gamma$ ) levels were analyzed using Mouse IFN- $\gamma$ ELISA Kit II (RUO) (BD Biosciences) according to manufacturer's protocol. Briefly, supernatants were diluted 1:10, $1: 20$ or $1: 100$ and plated along with the IFN- $\gamma$ standard serial dilutions in wells containing $50 \mu \mathrm{L}$ ELISA Diluent and incubated for 2 hours. Wells were washed 5 times. Working Detector $(100 \mu \mathrm{L})$ was added to each well and incubated for 1 hour. Wells were washed 7 times. TMB One-step Substrate Reagent $(100 \mu \mathrm{L})$ was added to each well and incubated for $30 \mathrm{~min}$. Stop Solution $(50 \mu \mathrm{L})$ was added to each well and absorbance was read at 450 and $570 \mathrm{~nm}$. 
A

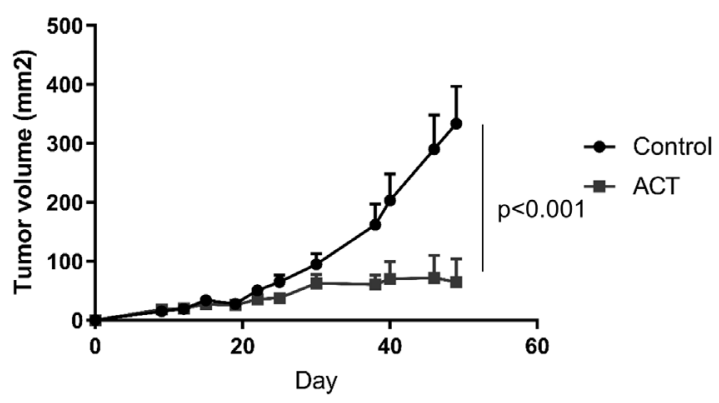

C

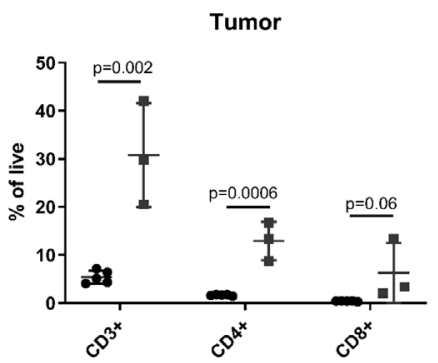

B
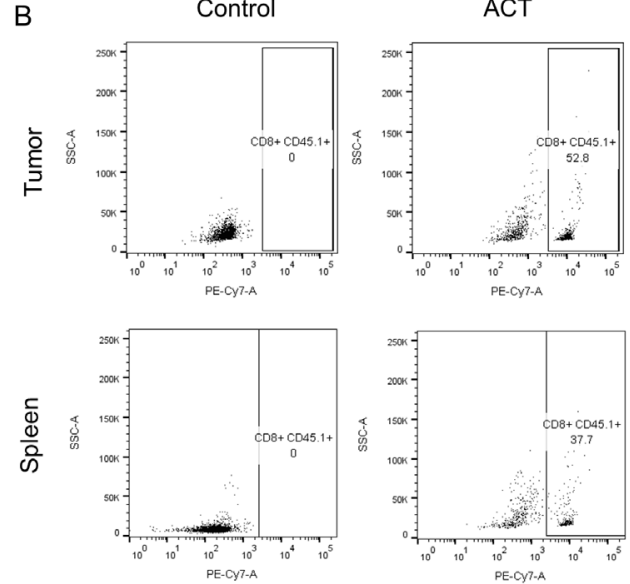

CD8+ CD45.1+
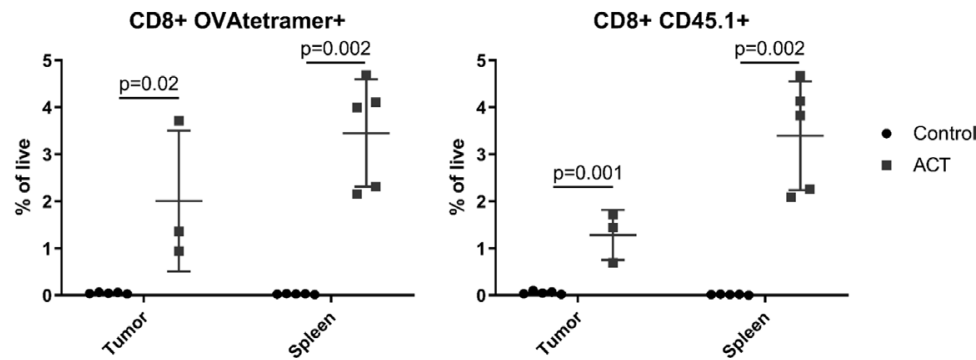

Figure 2 Systemic adoptive cellular therapy (ACT) using OT-I T cells decreases ovalbumin (OVA) expressing MB49 tumor cell line (MB49OVA) subcutaneous tumor growth. Mice were injected subcutaneously with MB49OVA tumors. Mice were treated with lymphodepleting chemotherapy followed by OT-I T cells or phosphate-buffered saline (PBS) by tail-vein injection. Mice received interleukin-2 injections every 12 hours for 3 days following ACT. (A) ACT-treated mice had a reduction in tumor growth compared with PBS-treated mice. On day 50, tumors and spleen were collected and analyzed for CD8 ${ }^{+} \mathrm{T}$ cells, CD45. $1^{+} \mathrm{CD} 8^{+} \mathrm{T}$ cells and OVA tetramer ${ }^{+} \mathrm{CD} 8^{+} \mathrm{T}$ cells by flow cytometry (B representative flow plots, $\mathrm{C}$ averaged data). $\mathrm{n}=5$ per group. Repeated 3 times.

\section{Blocking CXCR3}

OT-I T cells were isolated as described and incubated for 30 min on ice with either normal rat IgG isotype control or CXCR3 blocking antibody (500 $\mu \mathrm{g}$, catalog\# BE0249, BioXcell). In vitro, OT-I T cells were plated in normal $\mathrm{CM}$ in the upper well of a Corning Transwell insert with MB49OVA tumor digest conditioned media in the bottom. Cells were collected from the bottom chamber and counted 24 hours later. In vivo, mice were inoculated with orthotopic MB49OVA tumors as described above. Tumor-bearing mice were randomized and treated with antibody-coated OT-I T in $100 \mu \mathrm{L}$ of PBS cells on day 7 . Tumors were collected 3 and 24 hours after instillation, washed 3 times in PBS, digested and analyzed for CD45.1 ${ }^{+}$ $\mathrm{T}$ cell infiltration by flow cytometry. An additional cohort was monitored for tumor growth by ultrasound-guided imaging every $2-3$ days.

\section{Patient subjects}

Two human bladder cancer TIL samples were screened for CXCR3 (catalog\# 562558, BD Biosciences) expression by flow cytometry as described above. Informed consent was obtained prior to surgical resection under an IRB-approved study (MCC 18142). Both samples were from patients with muscle-invasive bladder cancer undergoing radical cystectomy. One patient had neoadujvent cisplatin-based chemotherapy and one patient did not receive chemotherapy. TIL was expanded as previously described. ${ }^{26}$

\section{Statistical analysis}

For comparison of in vitro studies with two experimental groups, a Student's t-test was performed. For in vitro studies with more than two experimental groups, a one-way analysis of variance (ANOVA) was performed, followed by a Tukey's post hoc comparison. For in vivo studies with two groups, the CGGC permutation test was used. ${ }^{27}$ For in vivo studies with three or more treatment groups, a two-way ANOVA (Tukey's post hoc) was performed at each time point. GraphPad Prism was used to perform statistical analysis. Data with a $\mathrm{p}$ value $<0.05$ were deemed statistically significant.

\section{RESULTS MB490VA transduced cells express OVA and are recognized by $0 T-I T$ cells}

In order to study antigen-specific $\mathrm{T}$ cell response using ACT, we developed a model using a strong antigen and target T cell. MB49 cells were transduced to express OVA which is recognized by OT-I T cells. OT-I mice are transgenic mice containing TCR $\alpha$-V2 and TCR $\beta$-V5 specific for OVA peptide residues 257-264 in the context of $\mathrm{H}_{2} \mathrm{~K}^{\mathrm{b}}$. Figure 1A,B show successful incorporation of ZsGOVA 
A

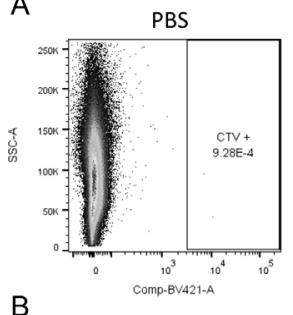

B

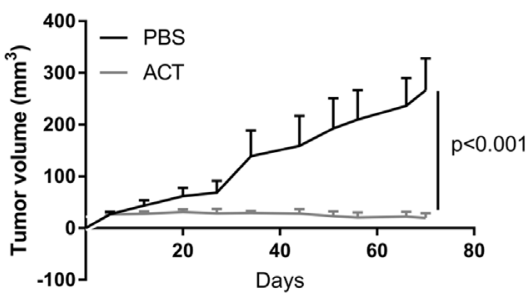

C
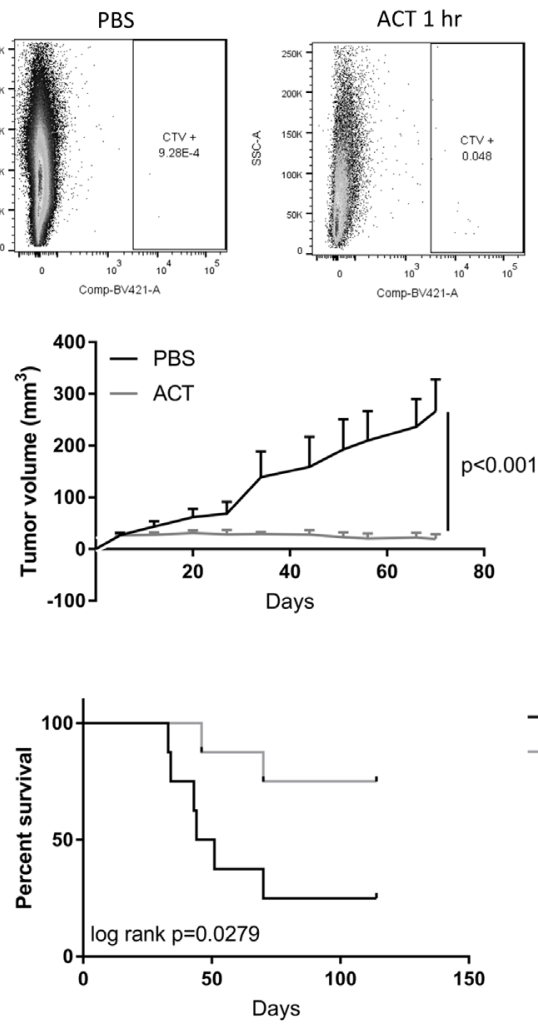

$\mathrm{D}$
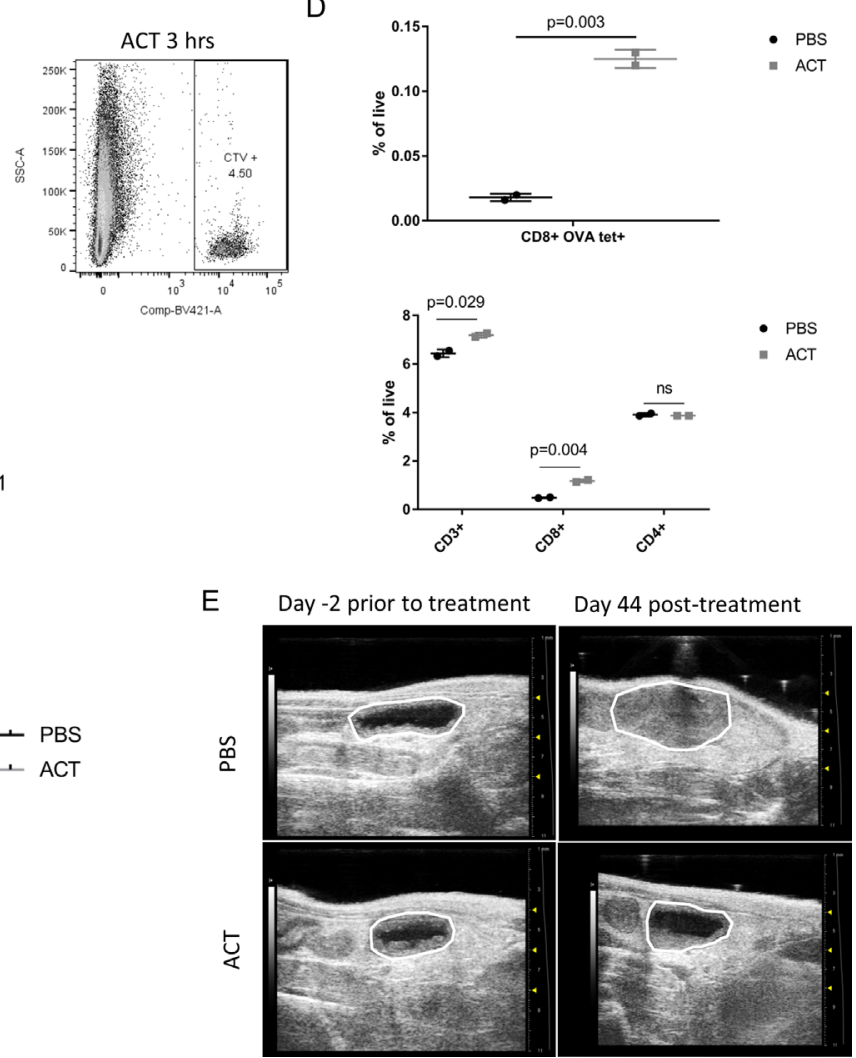

Figure 3 Intravesical adoptive cellular therapy (ACT) using OT-I T cells delays ovalbumin expressing MB49 tumor cell line (MB49OVA) orthotopic tumor growth. Mice were inoculated with orthotopic MB49OVA tumors. Mice were treated with OT-I cells labeled with CellTrace Violet (CTV) delivered intravesically. (A) After 3 hours of instillation, tumors were collected and analyzed for CTV-labeled OT-I T cells by flow cytometry. (B) Mice with MB49OVA orthotopic tumors were treated with unlabeled OTI T cells and monitored for tumor growth by ultrasound. ACT-treated mice had a reduction in tumor volume compared with phosphate-buffered saline (PBS)-treated mice and improved survival (C). (D) Tumors were collected on day 60 and analyzed for $\mathrm{CD}^{+}, \mathrm{CD}^{+}, \mathrm{CD}^{+}$and $\mathrm{CD}^{+}$OVA tetramer ${ }^{+} \mathrm{T}$ cells by flow cytometry. (E) Representative ultrasound images from mice in each treatment group -2 days prior to treatment and 44 days post-treatment. $\mathrm{N}=8$ per group. Repeated 3 times.

and surface expression of H2K $\mathrm{K}^{\mathrm{b}}$ SIINFEKL in MB49OVA cells as determined by flow cytometry. To confirm OT-I $\mathrm{T}$ cells are specific for MB49OVA cells, a co-culture was performed with the parental MB49 cell line, MB49OVA cell line and OVA SIINFEKL peptide as a positive control. IFN- $\gamma$ production was measured in the co-culture supernatants by an ELISA assay. OT-I T cells specifically recognize MB49OVA cells and not the parental MB49 cells that lack OVA (figure 1C). TILs were isolated from MB49OVA subcutaneous tumors in C57BL/6 mice and a co-culture assay was performed with the same conditions (figure 1D). TIL produced IFN- $\gamma$ after co-culture with MB49OVA cells and to a lesser degree with the parental MB49 cells. These data validate our MB49OVA/OT-I model, which will be used in subsequent experiments.

\section{Systemic ACT using OT-I T cells decreases tumor growth in MB490VA subcutaneous tumors}

To investigate the potential for systemic ACT to treat bladder cancer, MB49OVA cells $\left(5.0 \times 10^{5}\right)$ were injected subcutaneously into female C57BL/6 mice. Twenty days later when tumors were established, mice were randomized and treated with NMAC (cyclophosphamide/fludarabine) followed by intravenous infusion of OT-I CD8 ${ }^{+}$
$\mathrm{T}$ cells $\left(5.0 \times 10^{6}\right.$ cells/mouse $)$ and intraperitoneal injection of IL-2. ACT-treated mice had a reduction in tumor growth compared with control-treated mice (figure 2A). On day 50, tumors and spleens were processed, and immune cell populations were examined by flow cytometry. CD $45.1^{+} \mathrm{T}$ cells, a congenic marker used to distinguish the transferred OT-I T cells from the recipient mice $\mathrm{T}$ cells, were detected both in the spleen and tumors of ACT-treated mice and not detected in control-treated mice (figure 2B,C). In addition, there was an increase in $\mathrm{CD}^{+}$and $\mathrm{CD}^{+}$and $\mathrm{CD} 8^{+} \mathrm{OVA}$ tetramer ${ }^{+} \mathrm{T}$ cells in the tumors of ACT-treated mice (figure 2C). An increase in $\mathrm{CD}^{+} \mathrm{OVA}^{-}$tetramer ${ }^{+} \mathrm{T}$ cells was also measured in the spleens of treated mice (figure $2 \mathrm{C}$ ), with no difference in total T cells (online supplemental figure 1A). ACT-treated mice that had complete tumor regression were subsequently challenged with the parental MB49 subcutaneous tumors 100 days later. All mice rejected MB49 tumors compared with naive mice (online supplemental figure 2A). Splenocytes taken from re-challenged mice were able to produce IFN- $\gamma$ in a co-culture with either MB49 or MB49OVA tumor cells (online supplemental figure 2B). Lastly, flow cytometric analysis of the splenocytes 

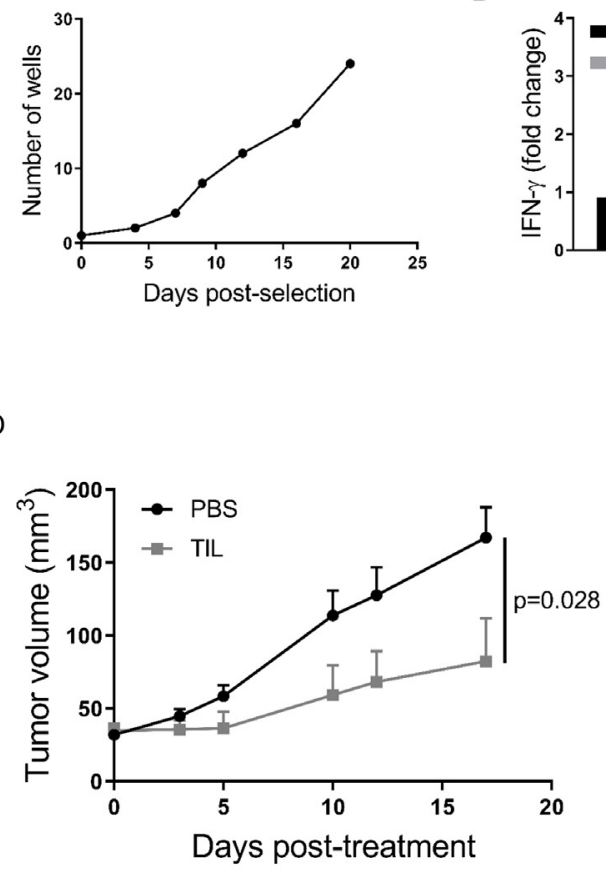

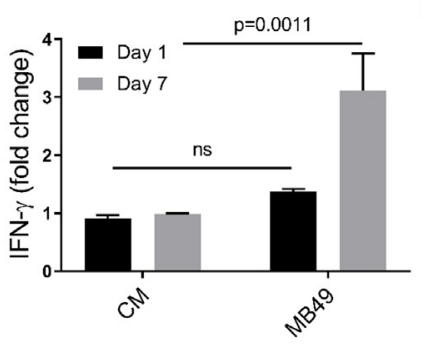

C

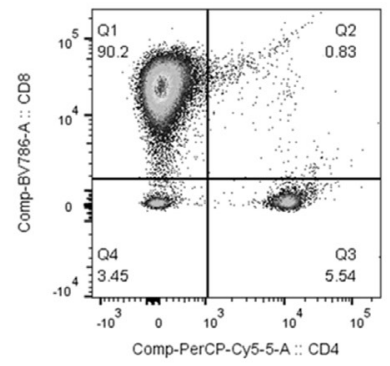

E

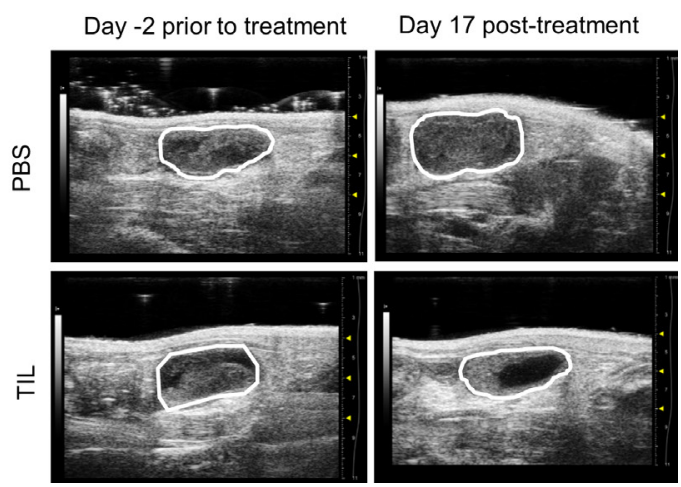

Figure 4 Intravesical adoptive cellular therapy (ACT) using murine tumor-infiltrating lymphocyte (TIL) from MB49 orthotopic tumors can delay orthotopic tumor growth. Donor mice were given MB49 orthotopic tumors. (A) TIL was isolated from tumor digest by CD90.2+ magnetic separation and expanded in $100 \mathrm{IU}$ of interleukin-2 for up to 25 days. (B) Expanded TIL was tested 1 and 7 days postisolation by co-culturing with MB49 tumor cells and assayed for IFN- $\gamma$ production by ELISA. (C) Expanded TILs were predominantly CD8 ${ }^{+} \mathrm{T}$ cells as determined by flow cytometry. Recipient mice with orthotopic MB49 bladder tumors were treated intravesically with MB49-derived TIL. ACT-treated mice had a decrease in tumor volume (D) as measured by ultrasound (E). N=8. Repeated 2 times. CM, Complete Medium; ns, not significant; PBS, phosphate-buffered saline.

confirmed the presence of both CD45.1 $1^{+} \mathrm{CD} 8 \mathrm{~T}$ cells and OVA tetramer ${ }^{+} \mathrm{CD} 8 \mathrm{~T}$ cells over 100 days after adoptive transfer of OT-1 T cells. These data suggest that systemic ACT can decrease tumor burden in our model, and that adoptively transferred $\mathrm{T}$ cells can persist systemically. In addition, epitope spreading can occur as mice were able to reject rechallenge with the parental MB49 cell line lacking OVA.

\section{T cell migration into bladder tumors occurs within 3 hours after intravesical instillation}

To determine the potential to treat bladder tumors with intravesical TIL, we first determined how long it took T cells to migrate into the tumor. Mice were inoculated with MB49OVA cells $\left(1.0 \times 10^{5}\right)$ orthotopically. The presence of tumor in the bladder was confirmed by ultrasound-guided imaging. One-week post-tumor inoculation, tumorbearing mice were treated with OT-I CD $8^{+} \mathrm{T}$ cells $\left(4.0 \times 10^{6}\right.$ cells/mouse) label with CellTrace Violet (CTV). Mice were put under anesthesia for 1-3 hours with catheters in place to prevent the cells from leaking out of the bladder. Bladder tumors were collected and washed with PBS. Tumors were digested and analyzed by flow cytometry for the presence of CTV-labeled T cells. After 3 hours, $\mathrm{CTV}^{+}$ cells were detectable within the tumor digest (figure $3 \mathrm{~A}$ ). These data suggest that 3 hours is sufficient for $\mathrm{T}$ cells delivered intravesically to migrate into the tumor.

\section{Intravesical delivery of 0T-I T cells decreases tumor growth in MB490VA orthotopic tumors}

Next, to test the efficacy of intravesical ACT, mice were inoculated with MB49OVA orthotopic tumors. Oneweek later, tumor-bearing mice were randomized into two groups. Mice were placed under anesthesia for 3 hours and treated with OT-I CD8 ${ }^{+}$T cells $\left(4.0 \times 10^{6}\right.$ cells/mouse) or PBS. Tumor volume was monitored by ultrasound-guided imaging and quantified using Vevo Lab V.3.1.0 software. When mice reached end point, tumors and spleen were collected and processed. Flow cytometry analysis was performed to determine $\mathrm{T}$ cell infiltration as well as detect OVA tetramer ${ }^{+}$and CD 45. $1^{+}$adoptively transferred $\mathrm{T}$ cells. Intravesical ACT prevented tumor growth and improved survival compared with PBS-treated mice (figure 3B,C, representative ultrasound images figure $3 \mathrm{E}$ ). Treated mice had an increase in $\mathrm{CD}^{+}, \mathrm{CD}^{+}$and $\mathrm{OVA}$ tetramer ${ }^{+} \mathrm{T}$ cells within the tumor (figure 3D). No differences were seen in bulk $\mathrm{CD}^{+}, \mathrm{CD}^{+}, \mathrm{CD}^{+}$or $\mathrm{CD}^{+} \mathrm{OVA}$ tetramer ${ }^{+}$cell populations in the spleens, which was expected since this was a local therapy (online supplemental figure 1B-C). Results from this experiment confirmed intravesical $\mathrm{T}$ cell delivery can control tumor growth without lymphodepleting chemotherapy or IL-2. 
A
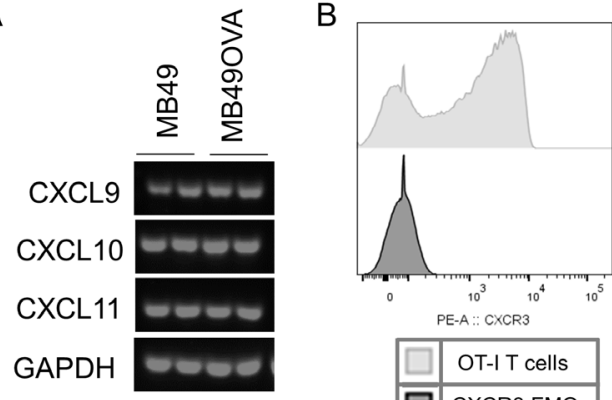

PE-A.: CXCR3

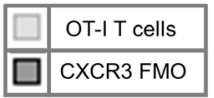

E

D

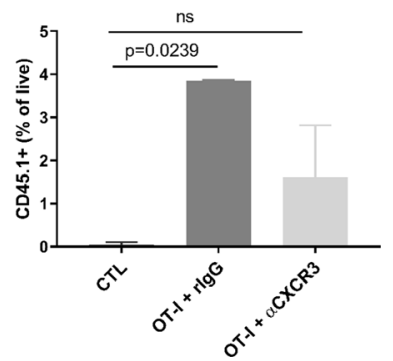

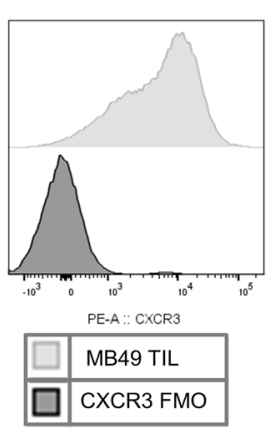

C
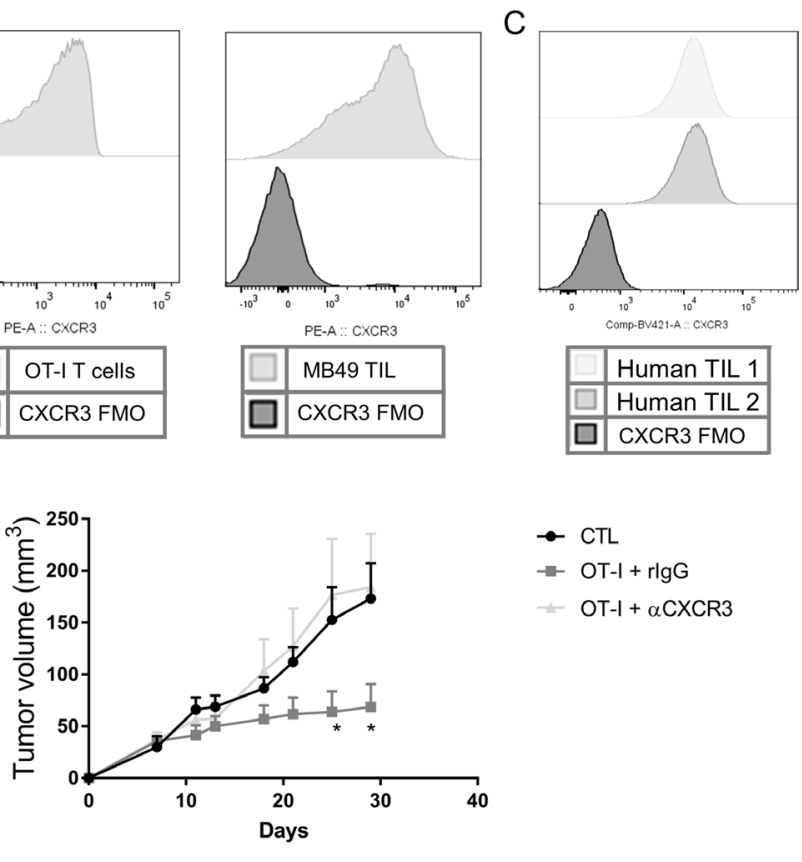

$\rightarrow$ CTL

- OT-I + rlgG

$-\mathrm{OT}-\mathrm{I}+\alpha \mathrm{CXCR} 3$

Figure 5 CXCR3 mediates T cell infiltration into orthotopic ovalbumin expressing MB49 tumor cell line (MB49OVA) bladder tumor from intravesical space. (A) RNA was isolated from MB49 and MB49OVA tumor cells and analyzed for expression of chemokines CXCL9, CXCL10 and CXCL11 as determined by PCR. (B) OT-I T cells were isolated from spleen of transgenic mice and tumor-infiltrating lymphocytes (TILs) were isolated from MB49 orthotopic tumors. Expression of CXCR3 was determined on these cell populations by flow cytometry. (C) TIL samples expanded from patient bladder tumors were analyzed for CXCR3 expression by flow cytometry. In vivo, mice were treated with OT-I T cells coated with a CXCR3 blocking antibody or rat IgG (rlgG). (D) Tumors were collected 3 and 24 hours after infusion and analyzed for $C D 45.1^{+} T$ cell infiltration by flow cytometry. (E) Tumor volume was measured by ultrasound. Precoating OT-I T cells with $\alpha$ CXCR3 decreased T cell infiltration into the tumor and abrogated the decrease in tumor growth seen with OT-I T cells coated with a control rlgG antibody. $N=5$ per group. Repeated 2 times. ns, not significant.

\section{TIL expansion from MB49 orthotopic tumors and intravesical ACT}

While an OVA-based tumor model can be used to optimize treatment strategies, OVA is a highly immunogenic foreign antigen and does not represent the antigens found in patient tumors. To more accurately model ACT using TILs, orthotopic MB49 tumors $\left(1.0 \times 10^{5}\right)$ were established in mice. Tumors were collected after 2 weeks and TILs were isolated. TILs were plated in 100 IU IL-2. Over the span of 25 days, TILs increased in number from $1.5 \times 10^{6}$ (1 well) to $39.2 \times 10^{6}$ (24 wells) as seen in figure $4 \mathrm{~A}$. IFN- $\gamma$ production was determined by ELISA after co-culturing TILs with MB49 tumor cells after 1 or 7 days in culture (figure 4B). The fold increase of IFN- $\gamma$ was highest after 7 days in culture compared with the CM condition. TILs were predominately $\mathrm{CD} 3^{+} \mathrm{CD}^{+} \mathrm{T}$ cells $(90.2 \%$, figure $4 \mathrm{C})$. Next, TILs isolated from 20 MB49 orthotopic tumors and expanded in culture for 7 days was adoptively transferred intravesically into mice bearing orthotopic MB49 tumors on day 8. Tumor growth was abrogated in mice treated with TILs compared with PBS control-treated mice (figure 4D, online supplemental figure 3). A representative image of PBS and TILs treated tumors -2 days prior to TILs delivery and 17 days after treatment started can be seen in figure $4 \mathrm{E}$. These data confirm intravesical TILs delivery can decrease tumor growth.

\section{CXCR3 is responsible for T cell infiltration into bladder tumors post-ACT}

Next, to determine a potential mechanism by which adoptively transferred $\mathrm{T}$ cells migrate from the intravesical space into bladder tumors, we first screened orthotopic MB49 and MB49OVA bladder tumors for the chemokines CXCL9, CXL10, CXCL11 by PCR after tumor digestion and RNA isolation (figure 5A). We then confirmed expression of $\mathrm{T}$ cell activation and migration marker CXCR3, which binds CXCL9/10/11, on OT-I T cells, MB49 TIL and two patient TIL samples by flow cytometry (figure 5B,C). Blocking CXCR3 decreased migration of OT-I T cells in vitro (online supplemental figure 4). Next, we adoptively transferred OT-I T cells $\left(3.5 \times 10^{6}\right)$ into the bladders of mice bearing orthotopic MB49OVA tumors. T cells were coated with a CXCR3 blocking antibody or control normal rat IgG prior to intravesical delivery (online supplemental figure 4). Two mice per group were euthanized at 3 and 24 hours after transfer. Tumors were collected and screened for CD 45. $1^{+}$ $\mathrm{T}$ cells (figure $5 \mathrm{D}$ ). Mice treated with $\mathrm{T}$ cells coated with $\alpha$ CXCR3 antibodies had a reduction in CD45.1 $1^{+} \mathrm{T}$ cells within the tumor at both time points. In a second cohort of mice, tumor growth was monitored by ultrasound after treatment. CXCR3 antibody-coated OT-I T cells were not able to delay tumor growth compared with control rat 
IgG-coated OT-I T cells (figure 5E). These data suggest that CXCR3 is at least in part responsible for $\mathrm{T}$ cell infiltration into bladder tumors from the intravesical space.

\section{DISCUSSION}

In this study, we have demonstrated the ability of TIL delivered systemically or intravesically to delay tumor growth in a murine model. In traditional ACT, TIL is administered systemically in a single dose after NMAC and followed with systemic IL-2 therapy. ${ }^{20}{ }^{21}$ Bladder cancer provides us with a unique opportunity to capitalize on the potential power of TIL therapy by using multiple modalities of tissue collection and different delivery routes to target multiple stages of the disease. First, tumor tissue obtained from either TURBT, radical cystectomy or biopsy of distant metastases could potentially be used as a source of TIL. ${ }^{26}$ Second, TIL therapy could be administered by different routes; systemic delivery could treat patients with metastatic bladder cancer or those who have undergone a cystectomy and intravesical delivery could treat patients with NMIBC as a bladder-sparing treatment option. Patients with MIBC could potentially receive TIL in a neoadjuvant or adjuvant setting. Systemic TIL therapy could also be combined with systemic immune checkpoint inhibitors, which has been shown to improve the efficacy of ACT in patients with metastatic melanoma. ${ }^{29}$ We anticipate intravesical TIL delivery would abrogate the need for NMAC and systemic IL-2. This would greatly reduce toxicity associated with TIL therapy. Additionally, intravesical TIL therapy has the potential to be delivered multiple times and could be given in combination with intravesical IL-2 without the toxic side effects associated with systemic IL-2. ${ }^{30}$

We have shown using a model with a strong antigen that either systemic or intravesical delivery of tumor-reactive $\mathrm{T}$ cells can elicit a profound antitumor response. After systemic OT-I T cell delivery, adoptively transferred $\mathrm{T}$ cells were detected within the mouse over 100 days after transfer, suggesting long-term systemic survival. Additionally, mice that were re-challenged with MB49 tumor cells that lack OVA completely rejected tumor growth. This suggests epitope spreading has occurred and that $\mathrm{T}$ cells were educated against other mutations and/or neoantigens in MB49 tumor cells.

Unlike our OVA/OT-I experimental model, TILs expanded from patient tumor samples represents a heterogeneous $\mathrm{T}$ cell population with varying degrees of activation and tumor specificity. To model TIL therapy more accurately, we expanded TILs from orthotopic MB49 tumors ex vivo and tested for reactivity against MB49 tumor cells. TILs were then used to treat recipient mice with orthotopic MB49 tumors and was able to delay tumor growth. We were also able to identify an important role of CXCR3 in $\mathrm{T}$ cell migration from the intravesical space into the tumor. CXCR3 is expressed by human TIL samples and human bladder tumors have been shown to overexpress CXCL9, CXCL10 and CXCL11. ${ }^{31-35}$ We may be able to exploit this signaling pathway to increase the efficacy of TIL therapy. However, there may be other factors, such as cell-adhesion molecules and integrin signaling, which promote $\mathrm{T}$ cell attachment and infiltration into the tumor.

Moving forward, we will continue to investigate the optimal treatment approach for both systemic and intravesical TIL delivery, including combination treatments with anti-PD-1 or anti-PD-L1 immunotherapy. Future studies will investigate ways to improve $\mathrm{T}$ cell infiltration into tumors and decrease immunosuppressive cell populations, such as regulatory $\mathrm{T}$ cells and myeloid-derived suppressor cells, within the tumor microenvironment. Taken together, these studies suggest ACT of TIL has potential to treat patients with bladder cancer and could greatly improve the quality of life of patients.

Acknowledgements The authors would like to thank University of South Florida Comparative Medicine staff for housing and husbandry of all mice. The authors would also like to thank the Flow Cytometry Core Facility and the Small Animal Imaging Lab at Moffitt Cancer Center for use of their equipment and facilities.

Contributors Conception and design: SP-T, BLB, MB. Development and methodology: BLB, JM, PI. Acquisition of data: BLB, JM, SA, JB, AMA. Analysis and interpretation of data: BLB, SP-T, MP. Writing, review and/or revision of the manuscript: BLB, AMA, AH, MP, SP-T. Administrative, technical or material support: BLB, JM, SA, JB. Study supervision: SP-T, BLB, MP.

Funding This work was supported in part by the Cancer Center Support Grant P30 CA076292 from the National Cancer Institute, American Cancer Society-Leo and Anne Albert Charitable Foundation Research Scholar Grant (RSG-16-117-01-LIB), Swim Across America and the Junior Scientist Research Partnership Award at Moffitt Cancer Center. All animal experiments were approved by the Institutional Animal Care and Use Committee at the University of South Florida.

Competing interests Moffitt Cancer Center has licensed Intellectual Property (IP) related to the proliferation and expansion of tumor-infiltrating lymphocytes to lovance Biotherapeutics. Moffitt has also licensed IP to Tuhura Biopharma. SP-T is an inventor on such IP. SP-T participates in sponsored research agreements with Provectus Biopharmaceuticals, lovance Biotherapeutics, Intellia Therapeutics and Myst Therapeutics that are not related to this research. SP-T has received research support that is not related to this research from the following entities: State of Florida Bankhead-Coley Cancer Research Program (7BC08), NIH-NCl (U01 CA244100-01 and R01 CA239219-01A1) and V Foundation. Additionally, SP-T is a co-investigator on NIH-NCI (U54 CA193489-01A1 and R01 CA241559) research support, which is not related to this research.

Patient consent for publication Not required.

Ethics approval Animal studies have been approved by the Institutional Animal Care and Use Committee at University of South Florida. Patient consent was obtained prior to surgical resection of human bladder specimens; the study was approved and overseen by the Institutional Review Board (MCC18142).

Provenance and peer review Not commissioned; externally peer reviewed.

Data availability statement Data are available on reasonable request. Data available on request.

Supplemental material This content has been supplied by the author(s). It has not been vetted by BMJ Publishing Group Limited (BMJ) and may not have been peer-reviewed. Any opinions or recommendations discussed are solely those of the author(s) and are not endorsed by BMJ. BMJ disclaims all liability and responsibility arising from any reliance placed on the content. Where the content includes any translated material, BMJ does not warrant the accuracy and reliability of the translations (including but not limited to local regulations, clinical guidelines, terminology, drug names and drug dosages), and is not responsible for any error and/or omissions arising from translation and adaptation or otherwise.

Open access This is an open access article distributed in accordance with the Creative Commons Attribution Non Commercial (CC BY-NC 4.0) license, which permits others to distribute, remix, adapt, build upon this work non-commercially, and license their derivative works on different terms, provided the original work is 
properly cited, appropriate credit is given, any changes made indicated, and the use is non-commercial. See http://creativecommons.org/licenses/by-nc/4.0/.

\section{ORCID iDs}

Brittany L Bunch http://orcid.org/0000-0001-7302-8360

Patrick Innamarato http://orcid.org/0000-0001-7601-1134

\section{REFERENCES}

1 Siegel RL, Miller KD, Jemal A. Cancer statistics, 2020. CA Cancer J Clin 2020;70:7-30.

2 Cassell A, Yunusa B, Jalloh M, et al. Non-Muscle invasive bladder cancer: a review of the current trend in Africa. World $\mathrm{J}$ Oncol 2019;10:123-31.

3 Compérat $\mathrm{E}$, Larré $\mathrm{S}$, Roupret $\mathrm{M}$, et al. Clinicopathological characteristics of urothelial bladder cancer in patients less than 40 years old. Virchows Arch 2015;466:589-94.

4 Parekh DJ, Bochner BH, Dalbagni G. Superficial and muscleinvasive bladder cancer: principles of management for outcomes assessments. J Clin Oncol 2006;24:5519-27.

5 Chang SS, Boorjian SA, Chou R, et al. Diagnosis and treatment of non-muscle invasive bladder cancer: AUA/SUO guideline. $J$ Urol 2016;196:1021-9.

6 Soloway MS. Overview of treatment of superficial bladder cancer. Urology 1985;26:18-26 http://www.ncbi.nlm.nih.gov/pubmed/ 4049626

7 Messing EM. The BCG shortage. Bladder Cancer 2017;3:227-8.

8 Rosenberg JE, Hoffman-Censits J, Powles T, et al. Atezolizumab in patients with locally advanced and metastatic urothelial carcinoma who have progressed following treatment with platinum-based chemotherapy: a single-arm, multicentre, phase 2 trial. Lancet 2016;387:1909-20.

9 Ning Y-M, Suzman D, Maher VE, et al. Fda approval summary: Atezolizumab for the treatment of patients with progressive advanced urothelial carcinoma after Platinum-Containing chemotherapy. Oncologist 2017;22:743-9.

10 Powles T, Eder JP, Fine GD, et al. MPDL3280A (anti-PD-L1) treatment leads to clinical activity in metastatic bladder cancer. Nature 2014;515:558-62.

11 Plimack ER, Bellmunt J, Gupta S, et al. Safety and activity of pembrolizumab in patients with locally advanced or metastatic urothelial cancer (KEYNOTE-012): a non-randomised, open-label, phase 1B study. Lancet Oncol 2017;18:212-20.

12 Sharma P, Callahan MK, Bono P, et al. Nivolumab monotherapy in recurrent metastatic urothelial carcinoma (CheckMate 032): a multicentre, open-label, two-stage, multi-arm, phase $1 / 2$ trial. Lancet Oncol 2016;17:1590-8.

13 Boegemann M, Aydin AM, Bagrodia A, et al. Prospects and progress of immunotherapy for bladder cancer. Expert Opin Biol Ther 2017;10:1-15.

14 Alhalabi O, Shah AY, Lemke EA, et al. Current and future landscape of immune checkpoint inhibitors in urothelial cancer. Oncology 2019;33:11-19 https://go-gale-com.gate.lib.buffalo.edu/ps/retrieve. do?tabID=T002\&resultListType=RESULT_LIST\&searchResultsType $=$ SingleTab\&searchType=AdvancedSearchForm\&currentPosition= 1\&docld=GALE\%7CA574566746\&docType=Report\&sort = RELEVANCE\&contentSegment=ZONE-MOD1\&prodld=AONE\& contentSet=GALE\%7CA574566746\&searchld=R1\&userGroupName= sunybuff_main\&inPS=true\&ps $=1 \& \mathrm{cp}=1$

15 Mari A, Campi R, Tellini R, et al. Patterns and predictors of recurrence after open radical cystectomy for bladder cancer: a comprehensive review of the literature. World J Urol 2018;36:157-70.
16 Bellmunt J, Théodore C, Demkov T, et al. Phase III trial of vinflunine plus best supportive care compared with best supportive care alone after a platinum-containing regimen in patients with advanced transitional cell carcinoma of the urothelial tract. $J$ Clin Oncol 2009;27:4454-61.

17 Sternberg CN, Yagoda A, Scher HI, et al. M-VAC (methotrexate, vinblastine, doxorubicin and cisplatin) for advanced transitional cell carcinoma of the urothelium. J Urol 1988;139:461-9.

18 Halford Z, Anderson MK, Clark MD. Enfortumab Vedotinejfv: a first-in-class Anti-Nectin-4 antibody-drug conjugate for the management of urothelial carcinoma. Ann Pharmacother 2020;18:106002802096040.

19 Loriot Y, Necchi A, Park SH, et al. Erdafitinib in locally advanced or metastatic urothelial carcinoma. N Engl J Med 2019;381:338-48.

20 Pilon-Thomas S, Kuhn L, Ellwanger S, et al. Efficacy of adoptive cell transfer of tumor-infiltrating lymphocytes after lymphopenia induction for metastatic melanoma. J Immunother 2012;35:615-20.

21 Rosenberg SA, Yang JC, Sherry RM, et al. Durable complete responses in heavily pretreated patients with metastatic melanoma using T-cell transfer immunotherapy. Clin Cancer Res 2011;17:4550-7.

22 Cancer Genome Atlas Research Network. Comprehensive molecular characterization of urothelial bladder carcinoma. Nature 2014;507:315-22.

23 Burger M, Catto JWF, Dalbagni G, et al. Epidemiology and risk factors of urothelial bladder cancer. Eur Urol 2013;63:234-41.

24 Robertson AG, Kim J, Al-Ahmadie H, et al. Comprehensive molecular characterization of muscle-invasive bladder cancer. Cell 2017;171:540-56.

25 Sharma P, Shen Y, Wen S, et al. Cd8 tumor-infiltrating lymphocytes are predictive of survival in muscle-invasive urothelial carcinoma. Proc Natl Acad Sci U S A 2007;104:3967-72.

26 Poch M, Hall M, Joerger A, et al. Expansion of tumor infiltrating lymphocytes (TIL) from bladder cancer. Oncoimmunology 2018;7:e1476816.

27 Zaharoff DA, Hoffman BS, Hooper HB, et al. Intravesical immunotherapy of superficial bladder cancer with chitosan/ interleukin-12. Cancer Res 2009;69:6192-9.

28 Huebner D, Rieger C, Bergmann R, et al. An orthotopic xenograft model for high-risk non-muscle invasive bladder cancer in mice: influence of mouse strain, tumor cell count, dwell time and bladder pretreatment. BMC Cancer 2017;17:790.

29 Elso CM, Roberts LJ, Smyth GK, et al. Leishmaniasis host response loci (Imr1-3) modify disease severity through a Th1/Th2-independent pathway. Genes Immun 2004;5:93-100.

30 Mullinax JE, Hall M, Prabhakaran S, et al. Combination of ipilimumab and adoptive cell therapy with tumor-infiltrating lymphocytes for patients with metastatic melanoma. Front Oncol 2018;8:44.

31 Den Otter W, Dobrowolski Z, Bugajski A, et al. Intravesical interleukin-2 in T1 papillary bladder carcinoma. $J$ Urol 1998;159:1183-6.

32 Nazari A, Ahmadi Z, Hassanshahi G, et al. Effective treatments for bladder cancer affecting CXCL9/CXCL10/CXCL11/CXCR3 axis: a review. Oman Med J 2020;35:e103.

33 Muthuswamy R, Wang L, Pitteroff $\mathrm{J}$, et al. Combination of IFN $\alpha$ and poly-I:C reprograms bladder cancer microenvironment for enhanced CTL attraction. $J$ Immunother Cancer 2015;3:6.

34 Wen J, Li H-zhong, Ji Z-gang, et al. [Expressions of receptor tyrosine kinases mRNA and protein in carcinoma of bladder]. Zhongguo $Y i$ Xue Ke Xue Yuan Xue Bao 2011;33:393-6.

35 Eckstein M, Strissel P, Strick R, et al. Cytotoxic T-cell-related gene expression signature predicts improved survival in muscle-invasive urothelial bladder cancer patients after radical cystectomy and adjuvant chemotherapy. J Immunother Cancer 2020;8:e000162. 